OPEN ACCESS

Edited by:

Terence Y. Pang,

Florey Institute of Neuroscience and

Mental Health, Australia

Reviewed by:

Ju Wang,

University of Virginia, USA

Konrad Prasad,

University of Pittsburgh School of Medicine, USA

Miguel L. Prieto,

Universidad de los Andes, Chile

*Correspondence:

Arup K. Dhar

arup.dhar@bakeridi.edu.au

Specialty section:

This article was submitted to

Molecular Psychiatry,

a section of the journal

Frontiers in Psychiatry

Received: 07 July 2015 Accepted: 25 February 2016

Published: 21 March 2016

Citation:

Dhar AK and Barton DA (2016)

Depression and the Link with

Cardiovascular Disease.

Front. Psychiatry 7:33.

doi: 10.3389/fpsyt.2016.00033

\section{Depression and the Link with Cardiovascular Disease}

\author{
Arup K. Dhar ${ }^{1,2,3 *}$ and David A. Barton ${ }^{1,2,3}$ \\ ${ }^{1}$ Human Neurotransmitters Laboratory, Baker IDI Heart and Diabetes Institute, Melbourne, VIC, Australia, ${ }^{2}$ Alfred Psychiatry, \\ Alfred Health, Melbourne, VIC, Australia, ${ }^{3}$ Faculty of Medicine, Nursing and Health Sciences, Monash University, Melbourne, \\ VIC, Australia
}

This review provides an outline of the association between major depressive disorder (MDD) and coronary heart disease (CHD). Much is known about the two individual clinical conditions; however, it is not until recently, biological mechanisms have been uncovered that link both MDD and CHD. The activation of stress pathways have been implicated as a neurochemical mechanism that links MDD and CHD. Depression is known to be associated with poorer outcomes of CHD. Psychological factors, such as major depression and stress, are now known as risk factors for developing $\mathrm{CHD}$, which is as important and is independent of classic risk factors, such as hypertension, diabetes mellitus, and cigarette smoking. Both conditions have great socioeconomic importance given that depression and CHD are likely to be two of the three leading causes of global burden of disease. Better understanding of the common causal pathways will help us delineate more appropriate treatments.

Keywords: depression, coronary heart disease, cardiac risk, cardiovascular disease, major depressive disorder

The known major links between CHD and MDD are outlined in this review. The search terms "depression, major depressive disorder, coronary heart disease, cardiac risk, cardiovascular disease," were entered into an electronic database, "PubMed." Articles published between 1950 and 2015, and written in English were chosen. Abstracts were then hand screened for relevance and were selected on the basis of addressing mechanisms associating MDD and CHD.

\section{DEPRESSION AND CORONARY HEART DISEASE PREVALENCE}

Major depression is a debilitating condition that presents with a number of cognitive and biological symptoms, including a pervasively lowered mood, anhedonia, negative cognitions, anergia, and appetite disturbance, and at its worst can manifest itself with suicidal thoughts and acts and psychotic features (1). The lifetime prevalence rates of major depression are in the order of $17 \%$. It is known that major depression is more prevalent in people who have suffered a major cardiac event, with up to $40 \%$ of patients meeting the criteria for major depressive disorder (MDD) (2). The large European Action on Secondary Prevention through Intervention to Reduce Events (EUROASPIRE) study showed potentially even higher rates with up to $35 \%$ of men and up to $65 \%$ of women measured as having depression on the hospital anxiety and depression scale (3). The enhancing recovery in coronary heart disease (ENRICHD) trial looked at patients who had recently suffered a myocardial infarction (MI), and depression was diagnosed in $74 \%$ of them (4). If we look at figures from the community through to those who are hospitalized, we see rates of depression of $10 \%$ in general practice clinics $(5,6)$, which then increases to up to $30 \%$ in those with coronary heart disease (CHD) in outpatient clinics (5-8), and up to a staggering $50 \%$ in those who are an inpatient for coronary artery bypass surgery $(6,9)$. 
The leading cause of mortality in the developed world is coronary artery disease (CAD). When cardiac disease and major depression present together, the prognosis for both worsen (10-12). Reviews have continually shown that major depression is associated with poorer quality of life (13) and increased morbidity (14-16) and mortality $(7-9,17,18)$. If MDD is present at baseline in a CHD patient, then it is an independent risk factor for poorer cardiovascular outcomes including MI (16).

A meta-analysis of 11 studies showed that MDD conferred an overall relative risk of 1.64 for developing CHD (19). The severity of the depression is proportional to the risk of developing CAD (20). Regarding mortality, MDD confers a relative risk of 1.8 in those suffering comorbid CHD (21). For those who have suffered a MI, the presence of MDD is a bad prognostic factor and carries a five times increased risk of cardiac mortality within 6 months (22).

\section{MECHANISMS OF MAJOR DEPRESSION AND INCREASED CARDIAC RISK}

It has long been accepted that there are numerous behavioral and lifestyle factors at play that confers increased CHD risk in those suffering depression. Psychological stress experienced by people suffering from MDD can also cause deregulation in the sympathetic nervous system and hypothalamic-pituitary-adrenal (HPA) axis $(23,24)$ (see Figure 1). This in turn has a number of deleterious downstream effects, including the development of hypertension, left ventricular hypertrophy (25), coronary vasoconstriction, endothelial dysfunction (26-28), platelet activation, and the production of pro inflammatory cytokines $(29,30)$ (see Table 1). The potential consequence of this is an elevated risk in ventricular arrhythmias (31) and MI (32).

\section{BEHAVIOURAL AND LIFESTYLE FACTORS}

It is well established that there are number of behavioral and lifestyle factors, which are present in MDD patients that can increase the chance of developing CHD (40). These include increased rates of smoking, alcohol intake, physical inactivity, and obesity (33). As seen with other medical conditions, major depression predicts poorer adherence responses in CHD patient to medications (41), lifestyle (42-44), and rehabilitation programs (45). In fact, non-completion rates in cardiac rehabilitation have been shown to be in the order of $44 \%$ compared to $29 \%$ in the non-depressed group (46). Therefore, we are likely to see the depressed CHD patient being less motivated and adherent to cardiac rehabilitation programs. MDD also makes it less likely to engage in lifestyle modification after a major cardiac event to reduce the classic risk factors of CHD. We see this with regards to cigarette smoking, where MDD patients are less likely to give up smoking and there consumption is also heavier (47).

\section{DISTURBANCE IN AUTONOMIC NERVOUS SYSTEM}

It has long been known that "stress" and heart disease are linked $(10,48)$. Stressful events, such as terrorist attacks (49), natural disasters (50), and even high stakes knockout soccer matches, have been positively associated with an increase in acute cardiovascular events (51). Mental stress is one of the many cognitive symptoms that people with major depression suffer from. Laboratory mental stress tests have been shown to activate sympathetic nervous outflow in the non-cardiac patient setting (52). The cardiac sympathetic nerves are preferentially activated by such mental stress (11). In animal models and the clinical setting (31, 53),

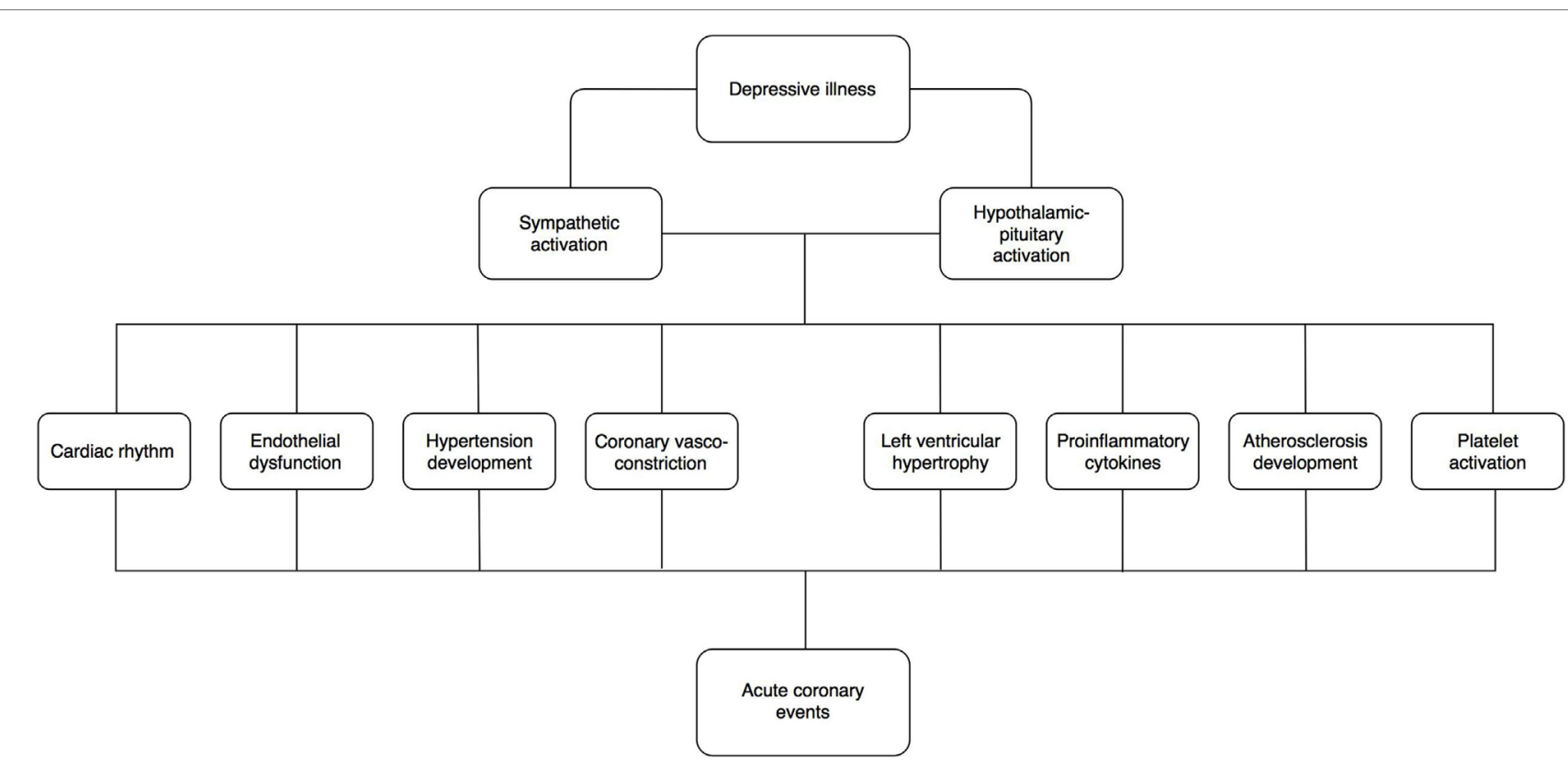

FIGURE 1 | Possible mechanisms whereby depression confers elevated cardiac risk. This is likely to be multifactorial including sympathetic activation, hypothalamic-pituitary activation, endothelial dysfunction, platelet activation, proinflammatory cytokines, and atherosclerosis development along with cardiac vascular and rhythm abnormalities. 
TABLE 1 | Summary of main findings in mechanisms of MDD and cardiac risk.

\begin{tabular}{|c|c|c|c|c|}
\hline Reference & Objective & Subjects & Methods & Results \\
\hline $\begin{array}{l}\text { Stapelberg } \\
\text { et al. (33) }\end{array}$ & $\begin{array}{l}\text { To identify a model of causal } \\
\text { mechanisms that link major } \\
\text { depressive disorder to } \\
\text { cardiovascular heart disease }\end{array}$ & - & A comprehensive literature review & $\begin{array}{l}\text { Mechanisms linking MDD and CHD that are often discussed } \\
\text { in the literature are genetic, behavioral, and immunological. } \\
\text { As well as coagulation, omega-3 PUFA deficiency and } \\
\text { vascular endothelial dysfunction. However, rather than } \\
\text { discussing them separately, these mechanisms should be } \\
\text { viewed as interdependent networks }\end{array}$ \\
\hline
\end{tabular}

Esler et al. To examine the sympathetic (23) nervous system function in depression

Carney et al. To examine whether depressed (34) patients with coronary artery disease (CAD) have lower heart rate variability compared with non-depressed CAD patients

Spieker et al. To identify the mechanisms (28) behind endothelial functioning in response to mental stress

Schlaich To determine possible

et al. (35) mechanisms leading to sympathetic augmentation in hypertension

Dinan (36) To review the biological markers of depression, specifically neuroendocrine disturbances and the hypothalamic-pituitaryadrenal axis (HPA)

Wong et al. To examine centrally directed norepinephrine and
corticotropin-releasing horm $(\mathrm{CRH})$ secretion in medicationfree patients with melancholic depression

Barton et al. To assess the significance of the 39 depressed

(38) sympathetic nervous system in patients the promotion of cardiac risk in 76 healthy subjects patients with MDD

Ghiadoni To explore whether mental stress 8 non-insulinet al. (27) promotes atherogenesis via dependent diabeti the impairment of endothelium- patients dependent vascular homeostasis 10 healthy subjects in preclinical subjects

Brown et al. To review the associations

(6) between MDD and CHD and address the clinical implications for treatment

Poole et al. To review the relationship

(39) between depression and adverse outcomes from acute coronary syndrome (ACS) and coronary artery bypass graft (CABG) surgery patients

1 depressed

patients

patients with

diagnosis patients CAD patients

22 hypertensive patients 11 normotensive patients

10 depressed

patients
19 depressed CAD Patients underwent 24-h Holter monitoring, with SD of normal-to19 non-depressed normal intervals were used as the primary index of heart rate variability

23 healthy subjects Nitroglyercin and flow-mediated (FMD) induced vasodilation were examined pre- and post-stress. FMD was also examined during stress

Norepinephrine and $\mathrm{CRH}$ were measured in lumbar cerebrospinal Microneurography and radio tracer dilution were used to measure regional sympathetic activity

A comprehensive literature review activation from the HPA. Other biological markers may be secondary to high glucocorticoid levels

Depressed patients had significantly higher levels of norepinephrine and plasma cortisol yet normal levels of $\mathrm{CRH}$. There was a negative correlation between plasma cortisol and $\mathrm{CRH}$ in healthy patients, while there was no relationship demonstrated in the depressed group cortisol secretion

Whole-body cardiac sympathetic activity was measured using noradrenaline isotope dilution methods and sympathetic nerve recording techniques

Response to sublingual glyceryl trinitrate and brachial artery flowmediated dilation (FMD) were

In healthy subjects, mental stress had no effect on the response to sublingual glyceryl trinitrate; however, FMD significantly reduced after. Without the stress stimuli, FMD

A bimodal distribution for whole body and heart sympathetic activity was demonstrated in patients with MDD. This subset of MDD patients had significantly high sympathetic activity measured before and after a mental was unchanged. While the diabetic group had lower FMD stress test. It was measured again in in comparison to controls, there were no changes following the healthy group, without a stress the stimuli for both FMD and sublingual glyceryl trinitrate stimuli on a separate occasion

A comprehensive literature review

While there is no evidence that treatment of depression will reduce this effect, it is still important to improve quality of life for those with depression through the benefits of psychological and pharmaceutical intervention

A comprehensive literature review Inflammation is a frequent causal process involved in the development of depressive symptoms and for adverse cardiac outcomes 
the significance of the activation of cardiac sympathetic cardiac fibers has demonstrated disturbances in heart rhythm, leading to increased risk of ventricular arrhythmias, decreased blood flow (54), left ventricular hypertrophy (25), and MI and sudden death (28). It has been shown that in depressed CHD patients, there is an elevated resting heart rate, and this also may be due to sympathetic hyperactivity in this group of patients (34).

Thus, it is postulated that the lowered removal of noradrenalin from the cardiac sympathetic synapse enhances the sympathetic stimulation and as a consequence confers CHD risk (38). In fact, it has been shown that there is a bimodal distribution of noradrenalin spill over in patients with MDD, with approximately one-third of patients exhibiting remarkably high levels (38). Interestingly, it has been shown that there is an elevated serotonin turnover in MDD patients who have not yet been treated with antidepressants, which is associated with the short allele of the serotonin transporter (55). This short allele has been also associated with increased urinary noradrenalin levels and therefore sympathetic over activity (56).

Hypertension is an established risk factor for the development of CHD. Up to $90 \%$ of patients with heart failure suffer from hypertension (28). Essential hypertension is often triggered and maintained by mental stress. The processes here include reduced uptake of noradrenalin (35) and activation of brain noradrenergic pathways and noradrenalin release from the heart. It has been demonstrated that there is indeed elevated noradrenalin levels in depressed patient's plasma and cerebrospinal fluid (57). We have seen other psychogenic causes of hypertension with the well-known phenomenon of white coat hypertension, which persists after numerous visits (58), where you would traditionally expect some form of desensitization to occur and blood pressures to normalize.

With regards to the parasympathetic system, a further possible mechanism linking MDD and CHD includes heart rate variability as a marker of vagal activity (59). Decreased heart variability (60-62) is associated with post-infarct mortality (63-66). Heart rate variability is modulated by the cardiac vagus and has been described in MDD patients (10).

\section{DISTURBANCE OF THE HYPOTHALAMIC-PITUITARY-ADRENAL AXIS}

Major depressive disorder has been implicated in the stressinduced activation of the HPA axis (36). Elevated levels of cortisol have repeatedly been found in $\operatorname{MDD}$ patients $(37,67,68)$. This hypercortisolemia causes an increased risk of a metabolic syndrome type state, which includes glucose intolerance, hyperlipidemia, and increased visceral fat mass (69-71). This metabolic syndrome not only confers a higher risk of cardiovascular disease (72) and diabetes (73) but has also been shown to drive sympathetic activation (74).

\section{PLATELET, INFLAMMATORY AND AUTOIMMUNE MECHANISMS}

Stress and anxiety, both common symptoms of major depression, can contribute to atherosclerosis (38). Increased platelet activation and endothelial dysfunction have been implicated as a potential pathophysiological pathway linking MDD and CHD $(75,76)$.

Prolonged mental stress, which is commonly experienced in those suffering from major depression, has been shown to induce prolonged endothelial dysfunction $(27,28)$. This endothelial dysfunction has been shown to be one of the early signs of future cardiovascular deterioration (77). In fact, oxidative stress itself has been described in numerous psychiatric illnesses (78).

Antiplatelet medication, such as aspirin, has long been a mainstay of preventative treatment of CHD (79). As stated, depression has been implicated with increased platelet reactivity (80), which will increase the relative risk of thrombus formation and arterial occlusion (10). MDD is associated with raised platelet serotonin levels, which promotes clotting (81). Further evidence of platelet activation can be shown by elevated levels of beta-thromboglobulin, which are raised in depressed CHD patients (80). It is this prothrombotic state, which leads to thrombus formation and consequently myocardial ischemia (17).

Inflammatory pathways have been proposed as one of the causal pathways responsible for MDD causing increased CHD risk (39), via atherosclerosis (82). Depressed patients have been found to have elevated levels of inflammatory markers, such as C-reactive protein (CRP), and proinflammatory cytokines, such as interleukin 1, 2, 6, and tumor necrosis factor (83-87). A number of these inflammatory markers have also been consistently associated with poor cardiovascular outcomes (88), and CRP can predict MI (89).

\section{IMPLICATIONS FOR TREATMENT}

Once major depression is present in those who have had a major cardiac event, we can expect them to still be suffering from depressive symptoms 4 months post discharge from hospital (90). It is important to recognize depression in $\mathrm{CHD}$, yet the majority of cases are not diagnosed or managed accordingly (91). In a consensus statement from the National Heart Foundation of Australia, they recommended that routine screening for depression is carried out for all patients suffering from CHD and first presentation and at follow-up (92). A perceived barrier to screening for depression by clinicians is lack of time (93). A quick and simple way to screen for depression in this setting would be to use a validated rating scale, such as the Cardiac Depression Scale (94).

The onset of a major depression has been shown to negatively moderate treatment outcomes for CHD patients (95). A recent Cochrane review showed that antidepressant medication was superior to placebo in the treatment of major depression in those who are also physically unwell.

Of the various antidepressants available to treat MDD, it is not known which is the best to lower the risk of CVD events in those suffering MDD (96). Common side effects of antidepressants must be taken into consideration when prescribing in those depressed CHD patients. This includes dizziness, appetite changes, sleep disturbance, gastrointestinal side effects, and sexual side effects.

Selective serotonin reuptake inhibitors (SSRIs) are the first-line pharmacotherapy for the treatment of major depression. This is generally because of their tolerability and safety 
profile $(97,98)$ and are deemed to be safe in the cardiac setting $(6,99)$. The SSRIs have been shown to have a meaningful effect on major depression (100). The Sertraline Antidepressant Heart Attack Randomized Trial (SADHART) demonstrated that the antidepressant sertraline improved depression in those who had suffered acute coronary syndrome (ACS) (101). The safety and efficacy of sertraline in the CHD group was evidenced in this study (101). The ENRICHD trial showed that antidepressant treatment improved CHD prognosis (102). In the review by (103), it was shown that antidepressant medication can positively alter physiological pathways linking MDD and CHD. We have stated that sympathetic over activity is important in causality of $\mathrm{CHD}$, and reductions in sympathetic activity have been shown following SSRI treatment (104). However, SSRIs are not without their flaws, and it has been noted that some induce weight gain and metabolic abnormalities (105-109).

There are various classes of antidepressants, such as the aforementioned selective SSRIs, tricyclic antidepressants (TCAs), and monoamine oxidase inhibitors (MAOIs). They are equally as efficacious (110), but differ significantly in their receptor and this side effect profiles. The TCAs and MAOIs are generally avoided in the treatment of major depression in those who have comorbid cardiac conditions, because of their toxic cardiac side effects (111). TCAs have been associated with elevated relative risk of 1.24 for CHD (112) and increased mortality rates in CHD (113). TCAs are also are also highly toxic in overdose (114), which is of concern to the prescribing clinician especially when treating those with a history of suicidal behavior. TCAs can cause QTc prolongation (115) and decrease heart rate variability (64) secondary to their anticholinergic effects.

With regards to psychological therapies for depression, such as cognitive behavioral therapy (CBT), they seem to be efficacious for the depression without being beneficial for CHD morbidity or mortality (116). The UK National Institute of Clinical Excellence's (NICE) guideline on depression in adults with chronic physical health problems advises that psychological treatment (such as CBT) be the first line of treatment for mild to moderate depression (110). However, this may not hold true for CHD patients and certainly is not the case for those suffering a more moderate to severe form of major depression, where biological treatment, such as antidepressants, are favored.

Physical exercise has long thought to be beneficial for one's mental state, and in the past, it was common to see exercise prescribed by their doctors, to aid with the treatment of major depression. A Cochrane review has indicated that moderate aerobic exercise in the order of $30 \mathrm{~min}$, five times a week is beneficial for relieving MDD symptoms. The magnitude of its efficacy should not be dismissed as Cochrane showed it had similar efficacy to CBT (117), and it of course will be beneficial to one's cardiovascular health. In those who exercise, it can be seen that depression, quality of life, and global functioning scores improve, thus decreasing the intensity and longevity of the episode of MDD (118). In the cardiac rehabilitation, setting exercise programs has not only shown to be beneficial for depression scores but also improves body percentage fat, triglyceride, and cholesterol levels (119).

In relation to platelet function, we have already discussed that platelet hyperactivity leads to a prothrombotic state, which in turn leads to increased risk of CHD. The SADHART platelet substudy showed a decreased platelet activation in those patients who had suffered an MI, were depressed, and had it treated with a SSRI, namely, sertraline (101). Paroxetine has also been shown to decrease platelet hyperactivity $(120,121)$. SSRIs have been shown to decrease sympathetic hyperactivity and, as a consequence, potentially reduce cardiac morbidity and mortality (38).

\section{CONCLUSION}

The underlying mechanism linking MDD and CHD are complex and multifactorial. As discussed, they involve the sympathetic nervous system, platelet hyperactivity, inflammation, and HPA dysregulation among others. Given that a definitive mortality study is unlikely to be done due to the complexities and costs involved, we are therefore guided by current evidence to maximize efficacy and potential harm when choosing our treatments for MDD who have comorbid CHD. We should be considering MDD as a common and modifiable risk factor for $\mathrm{CHD}$, just like we do for smoking, hypertension, hyperlipidemia, and the like. The toxic combination of MDD and CHD leads to poorer health outcomes for both conditions and escalating health-care costs. The implications for research is that further understanding of the pathophysiological mechanisms underpinning MDD and CHD is required so as to inform us of better treatments. It would be interesting to see not only studies looking at underlying biological mechanisms but also clinical ones. There needs to be an effort to try and minimize the barriers to screening and treating of MDD in those suffering from CHD. Given the bidirectionality of the conditions, it would also be useful to elucidate whether treatments for CHD can potentially decrease the intensity of symptom burden of MDD. Future clinical practice may include initiating cardioprotective medications alongside antidepressants when MDD is diagnosed, thus alleviating the morbidity, mortality, and cost burdens of MDD and CHD.

\section{AUTHOR CONTRIBUTIONS}

$\mathrm{AD}$ and $\mathrm{DB}$ made equal contribution to the preparation, revision and production of this review.

\section{ACKNOWLEDGMENTS}

The authors would like to thank Ms. Amy Lingard and Ms. Robyn Hemmes for their help in the preparation of this manuscript.

\section{FUNDING}

This study was funded by Baker IDI Heart and Diabetes Institute. 


\section{REFERENCES}

1. American Psychiatric Association. Diagnostic and Statistical Manual of Mental Disorders: DSM-5. Washington, DC: ManMag (2013).

2. Celano CM, Huffman JC. Depression and cardiac disease: a review. Cardiol Rev (2011) 19:130-42. doi:10.1097/CRD.0b013e31820e8106

3. Kotseva K, Wood D, De Backer G, De Bacquer D, Pyörälä K, Keil U, et al. EUROASPIRE III: a survey on the lifestyle, risk factors and use of cardioprotective drug therapies in coronary patients from 22 European countries. Eur J Cardiovasc Prev Rehabil (2009) 16:121-37. doi:10.1097/ HJR.0b013e3283294b1d

4. Carney RM, Blumenthal JA, Freedland KE, Youngblood M, Veith RC, Burg MM, et al. Depression and late mortality after myocardial infarction in the Enhancing Recovery in Coronary Heart Disease (ENRICHD) study. Psychosom Med (2004) 66:466-74. doi:10.1097/01.psy.0000133362.75075.a6

5. Cassano P, Fava M. Depression and public health: an overview. J Psychosom Res (2002) 53:849-57. doi:10.1016/S0022-3999(02)00304-5

6. Brown $\mathrm{AD}$, Barton DA, Lambert GW. Cardiovascular abnormalities in patients with major depressive disorder. CNS Drugs (2009) 23:583-602. doi:10.2165/00023210-200923070-00004

7. CarneyRM,RichMW,FreedlandKE,SainiJ,SimeoneC,ClarkK. Majordepressive disorder predicts cardiac events in patients with coronary artery disease. Psychosom Med (1988) 50:627-33. doi:10.1097/00006842-198811000-00009

8. Barefoot JC, Schroll M. Symptoms of depression, acute myocardial infarction, and total mortality in a community sample. Circulation (1996) 93:1976-80. doi:10.1161/01.CIR.93.11.1976

9. Ziegelstein RC. Depression in patients recovering from a myocardial infarction. JAMA (2001) 286:1621-7. doi:10.1001/jama.286.13.1621

10. Musselman DL, Evans DL, Nemeroff CB. The relationship of depression to cardiovascular disease: epidemiology, biology, and treatment. Arch Gen Psychiatry (1998) 55:580-92. doi:10.1001/archpsyc.55.7.580

11. Bunker SJ, Colquhoun DM, Esler MD, Hickie IB, Hunt D, Jelinek VM, et al. "Stress" and coronary heart disease: psychosocial risk factors. Med J Aust (2003) 178:272-6.

12. Rosengren A, Hawken S, Ôunpuu S, Sliwa K, Zubaid M, Almahmeed WA, et al. Association of psychosocial risk factors with risk of acute myocardial infarction in 11119 cases and 13648 controls from 52 countries (the INTERHEART study): case-control study. Lancet (2004) 364:953-62. doi:10.1016/S0140-6736(04)17019-0

13. Baumeister H, Balke K, Härter M. Psychiatric and somatic comorbidities are negatively associated with quality of life in physically ill patients. J Clin Epidemiol (2005) 58:1090-100. doi:10.1016/j.jclinepi.2005.03.011

14. Rugulies R. Depression as a predictor for coronary heart disease: a review and meta-analysis. Am J Prev Med (2002) 23:51-61. doi:10.1016/ S0749-3797(02)00439-7

15. Wulsin LR, Singal BM. Do depressive symptoms increase the risk for the onset of coronary disease? A systematic quantitative review. Psychosom Med (2003) 65:201-10. doi:10.1097/01.PSY.0000058371.50240.E3

16. Van Der Kooy K, Van Hout H, Marwijk H, Marten H, Stehouwer C, Beekman A. Depression and the risk for cardiovascular diseases: systematic review and meta analysis. Int J Geriatr Psychiatry (2007) 22:613-26. doi:10.1002/ gps. 1723

17. Barth J, Schumacher M, Herrmann-Lingen C. Depression as a risk factor for mortality in patients with coronary heart disease: a meta-analysis. Psychosom Med (2004) 66:802-13. doi:10.1097/01.psy.0000146332.53619.b2

18. Frasure-Smith N, Lespérance F, Talajic M. Depression and 18-month prognosis after myocardial infarction. Circulation (1995) 91:999-1005. doi:10.1161/01.CIR.91.4.999

19. Katon WJ, Lin EH, Russo J, Von Korff M, Ciechanowski P, Simon G, et al. Cardiac risk factors in patients with diabetes mellitus and major depression. J Gen Intern Med (2004) 19:1192-9. doi:10.1111/j.1525-1497.2004.30405.x

20. Glassman AH, Shapiro PA. Depression and the course of coronary artery disease. Am J Psychiatry (1998) 155(1):4-11. doi:10.1176/ajp.155.1.4

21. Nicholson A, Kuper H, Hemingway H. Depression as an aetiologic and prognostic factor in coronary heart disease: a meta-analysis of 6362 events among 146538 participants in 54 observational studies. Eur Heart J (2006) 27:2763-74. doi:10.1093/eurheartj/ehl338
22. Lange-Asschenfeldt C, Lederbogen F. [Antidepressant therapy in coronary arterydisease].Nervenarzt (2011) 82:657-64.doi:10.1007/s00115-010-3181-7

23. Esler M, Turbott J, Schwarz R, Leonard P, Bobik A, Skews H, et al. The peripheral kinetics of norepinephrine in depressive illness. Arch Gen Psychiatry (1982) 39:295-300. doi:10.1001/archpsyc.1982.04290030035006

24. Veith RC, Lewis N, Linares OA, Barnes RF, Raskind MA, Villacres EC, et al. Sympathetic nervous system activity in major depression: basal and desipramine-induced alterations in plasma norepinephrine kinetics. Arch Gen Psychiatry (1994) 51:411-22. doi:10.1001/archpsyc.1994.03950050071008

25. Schlaich MP, Kaye DM, Lambert E, Sommerville M, Socratous F, Esler MD. Relation between cardiac sympathetic activity and hypertensive left ventricular hypertrophy. Circulation (2003) 108:560-5. doi:10.1161/01. CIR.0000081775.72651.B6

26. Rubanyi GM. The role of endothelium in cardiovascular homeostasis and diseases. JCardiovasc Pharmacol (1993) 22:S1-4. doi:10.1097/00005344-199322004-00002

27. Ghiadoni L, Donald AE, Cropley M, Mullen MJ, Oakley G, Taylor M, et al. Mental stress induces transient endothelial dysfunction in humans. Circulation (2000) 102:2473-8. doi:10.1161/01.CIR.102.20.2473

28. Spieker LE, Hürlimann D, Ruschitzka F, Corti R, Enseleit F, Shaw S, et al. Mental stress induces prolonged endothelial dysfunction via endothelin-A receptors. Circulation (2002) 105:2817-20. doi:10.1161/01.CIR.0000021598.15895.34

29. Brydon L, Edwards S, Jia H, Mohamed-Ali V, Zachary I, Martin JF, et al. Psychological stress activates interleukin-1 $\beta$ gene expression in human mononuclear cells. Brain Behav Immun (2005) 19:540-6. doi:10.1016/j. bbi.2004.12.003

30. von Känel R, Kudielka BM, Preckel D, Hanebuth D, Fischer JE. Delayed response and lack of habituation in plasma interleukin- 6 to acute mental stress in men. Brain Behav Immun (2006) 20:40-8. doi:10.1016/j.bbi.2005.03.013

31. Meredith IT, Broughton A, Jennings GL, Esler MD. Evidence of a selective increase in cardiac sympathetic activity in patients with sustained ventricular arrhythmias. N Engl J Med (1991) 325:618-24. doi:10.1056/ NEJM199108293250905

32. Wittstein IS, Thiemann DR, Lima JA, Baughman KL, Schulman SP, Gerstenblith G, et al. Neurohumoral features of myocardial stunning due to sudden emotional stress. N Engl J Med (2005) 352:539-48. doi:10.1056/ NEJMoa043046

33. Stapelberg NJ, Neumann DL, Shum DH, Mcconnell H, Hamilton-Craig I. A topographical map of the causal network of mechanisms underlying the relationship between major depressive disorder and coronary heart disease. Aust N Z J Psychiatry (2011) 45:351-69. doi:10.3109/00048674.2011.570427

34. Carney RM, Saunders RD, Freedland KE, Stein P, Rich MW, Jaffe AS. Association of depression with reduced heart rate variability in coronary artery disease. Am J Cardiol (1995) 76:562-4. doi:10.1016/S0002-9149(99)80155-6

35. Schlaich MP, Lambert E, Kaye DM, Krozowski Z, Campbell DJ, Lambert $\mathrm{G}$, et al. Sympathetic augmentation in hypertension role of nerve firing, norepinephrine reuptake, and angiotensin neuromodulation. Hypertension (2004) 43:169-75. doi:10.1161/01.HYP.0000103160.35395.9E

36. Dinan TG. Glucocorticoids and the genesis of depressive illness. A psychobiological model. Br J Psychiatry (1994) 164:365-71. doi:10.1192/bjp.164.3.365

37. Wong M-L, Kling MA, Munson PJ, Listwak S, Licinio J, Prolo P, et al. Pronounced and sustained central hypernoradrenergic function in major depression with melancholic features: relation to hypercortisolism and corticotropin-releasing hormone. Proc Natl Acad Sci U S A (2000) 97:325-30. doi:10.1073/pnas.97.1.325

38. Barton DA, Dawood T, Lambert EA, Esler MD, Haikerwal D, Brenchley C, et al. Sympathetic activity in major depressive disorder: identifying those at increased cardiac risk? J Hypertens (2007) 25:2117-24. doi:10.1097/ HJH.0b013e32829baae7

39. Poole L, Dickens C, Steptoe A. The puzzle of depression and acute coronary syndrome: reviewing the role of acute inflammation. J Psychosom Res (2011) 71:61-8. doi:10.1016/j.jpsychores.2010.12.009

40. Joynt KE, Whellan DJ, O'Connor CM. Depression and cardiovascular disease: mechanisms of interaction. Biol Psychiatry (2003) 54:248-61. doi:10.1016/ S0006-3223(03)00568-7

41. Gehi A, Haas D, Pipkin S, Whooley MA. Depression and medication adherence in outpatients with coronary heart disease: findings from the 
Heart and Soul Study. Arch Intern Med (2005) 165:2508-13. doi:10.1001/ archinte.165.21.2508

42. Mayou RA, Gill D, Thompson DR, Day A, Hicks N, Volmink J, et al. Depression and anxiety as predictors of outcome after myocardial infarction. Psychosom Med (2000) 62:212-9. doi:10.1097/00006842-200003000-00011

43. Lane D, Carroll D, Ring C, Beevers DG, Lip GY. Mortality and quality of life 12 months after myocardial infarction: effects of depression and anxiety. Psychosom Med (2001) 63:221-30. doi:10.1097/00006842-200103000-00005

44. Kronish IM, Rieckmann N, Halm EA, Shimbo D, Vorchheimer D, Haas DC, et al. Persistent depression affects adherence to secondary prevention behaviors after acute coronary syndromes. J Gen Intern Med (2006) 21:1178-83. doi:10.1111/j.1525-1497.2006.00586.x

45. Lane D, Carroll D, Ring C, Beevers DG, Lip GY. Predictors of attendance at cardiac rehabilitation after myocardial infarction. J Psychosom Res (2001) 51:497-501. doi:10.1016/S0022-3999(01)00225-2

46. Swardfager W, Herrmann N, Marzolini S, Saleem M, Farber SB, Kiss A, et al. Major depressive disorder predicts completion, adherence, and outcomes in cardiac rehabilitation: a prospective cohort study of 195 patients with coronary artery disease. JClin Psychiatry (2011) 72:1181. doi:10.4088/ JCP.09m05810blu

47. John U, Meyer C, Rumpf H-J, Hapke U. Self-efficacy to refrain from smoking predicted by major depression and nicotine dependence. Addict Behav (2004) 29:857-66. doi:10.1016/j.addbeh.2004.02.053

48. Malzberg B. Mortality among patients with involution melancholia. Am J Psychiatry (1937) 93:1231-8. doi:10.1176/ajp.93.5.1231

49. Steinberg JS, Arshad A, Kowalski M, Kukar A, Suma V, Vloka M, et al. Increased incidence of life-threatening ventricular arrhythmias in implantable defibrillator patients after the World Trade Center attack. J Am Coll Cardiol (2004) 44:1261-4. doi:10.1016/j.jacc.2004.06.032

50. Leor J, Poole WK, Kloner RA. Sudden cardiac death triggered by an earthquake. N Engl J Med (1996) 334:413-9. doi:10.1056/NEJM199602153340701

51. Wilbert-Lampen U, Leistner D, Greven S, Pohl T, Sper S, Völker C, et al. Cardiovascular events during World Cup soccer. N Engl J Med (2008) 358:475-83. doi:10.1056/NEJMoa0707427

52. EslerM,JenningsG,LambertG.Measurementofoverallandcardiacnorepinephrine release into plasma during cognitive challenge. Psychoneuroendocrinology (1989) 14:477-81. doi:10.1016/0306-4530(89)90047-4

53. Kaye DM, Lefkovits J, Jennings GL, Bergin P, Broughton A, Esler MD. Adverse consequences of high sympathetic nervous activity in the failing human heart. J Am Coll Cardiol (1995) 26:1257-63. doi:10.1016/0735-1097(95)00332-0

54. L'Abbate A, Simonetti I, Carpeggiani C, Michelassi C. Coronary dynamics and mental arithmetic stress in humans. Circulation (1991) 83:II94-9.

55. Barton DA, Esler MD, Dawood T, Lambert EA, Haikerwal D, Brenchley C, et al. Elevated brain serotonin turnover in patients with depression: effect of genotype and therapy. Arch Gen Psychiatry (2008) 65:38-46. doi:10.1001/ archgenpsychiatry.2007.11

56. Otte C, Mccaffery J, Ali S, Whooley MA. Association of a serotonin transporter polymorphism (5-HTTLPR) with depression, perceived stress, and norepinephrine in patients with coronary disease: the Heart and Soul Study. Am J Psychiatry (2007) 164:1379-84. doi:10.1176/appi.ajp.2007.06101617

57. Gold PW, Wong M-L, Goldstein DS, Gold HK, Ronsaville DS, Esler M, et al. Cardiac implications of increased arterial entry and reversible 24-h central and peripheral norepinephrine levels in melancholia. Proc Natl Acad Sci U S A (2005) 102:8303-8. doi:10.1073/pnas.0503069102

58. Lambert EA, Schlaich MP. Reduced sympathoneural responses to the cold pressor test in individuals with essential hypertension and in those genetically predisposed to hypertension.* No support for the "pressor reactor" hypothesis of hypertension development. Am J Hypertens (2004) 17:863-8. doi:10.1016/S0895-7061(04)00844-1

59. Guzzetti S, Piccaluga E, Casati R, Cerutti S, Lombardi F, Pagani M, et al. Sympathetic predominance an essential hypertension: a study employing spectral analysis of heart rate variability. JHypertens (1988) 6:711-7. doi:10.1097/00004872-198809000-00004

60. Krittayaphong R, Cascio WE, Light KC, Sheffield D, Golden RN, Finkel JB, et al. Heart rate variability in patients with coronary artery disease: differences in patients with higher and lower depression scores. Psychosom Med (1997) 59:231-5. doi:10.1097/00006842-199705000-00004
61. Carney RM, Freedland KE, Stein PK, Skala JA, Hoffman P, Jaffe AS. Change in heart rate and heart rate variability during treatment for depression in patients with coronary heart disease. Psychosom Med (2000) 62:639-47. doi:10.1097/00006842-200009000-00007

62. Pitzalis MV, Iacoviello M, Todarello O, Fioretti A, Guida P, Massari F, et al. Depression but not anxiety influences the autonomic control of heart rate after myocardial infarction. Am Heart J (2001) 141:765-71. doi:10.1067/ mhj.2001.114806

63. Kleiger RE, Miller JP, Bigger JT, Moss AJ. Decreased heart rate variability and its association with increased mortality after acute myocardial infarction. Am J Cardiol (1987) 59:256-62. doi:10.1016/0002-9149(87)90795-8

64. Bigger JT, Fleiss JL, Steinman RC, Rolnitzky LM, Kleiger RE, Rottman JN. Frequency domain measures of heart period variability and mortality after myocardial infarction. Circulation (1992) 85:164-71. doi:10.1161/01. CIR.85.1.164

65. La Rovere MT, Bigger JT, Marcus FI, Mortara A, Schwartz PJ, Investigators A. Baroreflex sensitivity and heart-rate variability in prediction of total cardiac mortality after myocardial infarction. Lancet (1998) 351:478-84. doi:10.1016/S0140-6736(97)11144-8

66. Walther T, Wessel N, Baumert M, Stepan H, Voss A, Faber R. Longitudinal analysis of heart rate variability in chronic hypertensive pregnancy. Hypertens Res (2005) 28:113-8. doi:10.1291/hypres.28.113

67. Gold P, Chrousos G. Organization of the stress system and its dysregulation in melancholic and atypical depression: high vs. low CRH/NE states. Mol Psychiatry (2002) 7:254-75. doi:10.1038/sj.mp.4001032

68. Parker KJ, Schatzberg AF, Lyons DM. Neuroendocrine aspects of hypercortisolism in major depression. Horm Behav (2003) 43:60-6. doi:10.1016/ S0018-506X(02)00016-8

69. Björntorp P. Neuroendocrine abnormalities in human obesity. Metabolism (1995) 44:38-41. doi:10.1016/0026-0495(95)90208-2

70. Björntorp P, Rosmond R. The metabolic syndrome - a neuroendocrine disorder? Br J Nutr (2000) 83:S49-57. doi:10.1017/S0007114500000957

71. Björntorp P, Rosmond R. Neuroendocrine abnormalities in visceral obesity. Int. J Obes Relat Metab Disord (2000) 24:S80-5. doi:10.1038/ sj.ijo. 0801285

72. Malik S, Wong ND, Franklin SS, Kamath TV, Gilbert J, Pio JR, et al. Impact of the metabolic syndrome on mortality from coronary heart disease, cardiovascular disease, and all causes in United States adults. Circulation (2004) 110:1245-50. doi:10.1161/01.CIR.0000140677.20606.0E

73. Haffner SM, Valdez RA, Hazuda HP, Mitchell BD, Morales PA, Stern MP. Prospective analysis of the insulin-resistance syndrome (syndrome $\mathrm{X}$ ). Diabetes (1992) 41:715-22. doi:10.2337/diabetes.41.6.715

74. Straznicky NE, Lambert EA, Lambert GW, Masuo K, Esler MD, Nestel PJ. Effects of dietary weight loss on sympathetic activity and cardiac risk factors associated with the metabolic syndrome. JClin Endocrinol Metab (2005) 90:5998-6005. doi:10.1210/jc.2005-0961

75. Antman EM, Anbe DT, Armstrong PW, Bates ER, Green LA, Hand M, et al. ACC/AHA guidelines for the management of patients with ST-elevation myocardial infarction - executive summary: a report of the American College of Cardiology/American Heart Association Task Force on Practice Guidelines (Writing Committee to revise the 1999 guidelines for the management of patients with acute myocardial infarction). J Am Coll Cardiol (2004) 44:671-719. doi:10.1161/01.CIR.0000134791.68010.FA

76. Maes M, Meltzer HY, Bosmans E, Bergmans R, Vandoolaeghe E, Ranjan R, et al. Increased plasma concentrations of interleukin-6, soluble interleukin-6, soluble interleukin-2 and transferrin receptor in major depression. J Affect Disord (1995) 34:301-9. doi:10.1016/0165-0327(95)00028-L

77. Lerman A, Zeiher AM. Endothelial function cardiac events. Circulation (2005) 111:363-8. doi:10.1161/01.CIR.0000153339.27064.14

78. Chauvet-Gélinier J-C, Trojak B, Vergès-Patois B, Cottin Y, Bonin B. Review on depression and coronary heart disease. Arch Cardiovasc Dis (2013) 106:103-10. doi:10.1016/j.acvd.2012.12.004

79. Nemeroff CB, Musselman DL. Are platelets the link between depression and ischemic heart disease? Am Heart J (2000) 140:S57-62. doi:10.1067/ mhj.2000.109978

80. Laghrissi-Thode F, Wagner WR, Pollock BG, Johnson PC, Finkel MS. Elevated platelet factor 4 and $\beta$-thromboglobulin plasma levels in depressed patients 
with ischemic heart disease. Biol Psychiatry (1997) 42:290-5. doi:10.1016/ S0006-3223(96)00345-9

81. Sanner JE, Frazier L. The role of serotonin in depression and clotting in the coronary artery disease population. J Cardiovasc Nurs (2011) 26:423-9. doi:10.1097/JCN.0b013e3182076a81

82. Frasure-Smith N, Lespérance F. Reflections on depression as a cardiac risk factor. Psychosom Med (2005) 67:S19-25. doi:10.1097/01. psy.0000162253.07959.db

83. Maes M, Vandoolaeghe E, Ranjan R, Bosmans E, Bergmans R, Desnyder R. Increased serum interleukin-1-receptor-antagonist concentrations in major depression. JAffect Disord (1995) 36:29-36. doi:10.1016/0165-0327(95)00049-6

84. Miller GE, Stetler CA, Carney RM, Freedland KE, Banks WA. Clinical depression and inflammatory risk markers for coronary heart disease. Am J Cardiol (2002) 90:1279-83. doi:10.1016/S0002-9149(02)02863-1

85. Alesci S, Martinez PE, Kelkar S, Ilias I, Ronsaville DS, Listwak SJ, et al. Major depression is associated with significant diurnal elevations in plasma interleukin-6 levels, a shift of its circadian rhythm, and loss of physiological complexity in its secretion: clinical implications. JClin Endocrinol Metab (2005) 90:2522-30. doi:10.1210/jc.2004-1667

86. Leo R, Di Lorenzo G, Tesauro M, Razzini C, Forleo GB, Chiricolo G, et al. Association between enhanced soluble CD40 ligand and proinflammatory and prothrombotic states in major depressive disorder: pilot observations on the effects of selective serotonin reuptake inhibitor therapy. J Clin Psychiatry (2006) 67:1760-6. doi:10.4088/JCP.v67n1114

87. Dawood T, Lambert EA, Barton DA, Laude D, Elghozi J, Esler MD, et al. Specific serotonin reuptake inhibition in major depressive disorder adversely affects novel markers of cardiac risk. Hypertens Res (2007) 30:285. doi:10.1291/hypres.30.285

88. Danesh J, Collins R, Peto R. Chronic infections and coronary heart disease: is there a link? Lancet (1997) 350:430-6. doi:10.1016/S0140-6736(97)03079-1

89. Blake GJ, Rifai N, Buring JE, Ridker PM. Blood pressure, C-reactive protein, and risk of future cardiovascular events. Circulation (2003) 108:2993-9. doi:10.1161/01.CIR.0000104566.10178.AF

90. Thombs BD, Bass EB, Ford DE, Stewart KJ, Tsilidis KK, Patel U, et al. Prevalence of depression in survivors of acute myocardial infarction. J Gen Intern Med (2006) 21:30-8. doi:10.1111/j.1525-1497.2005.00269.x

91. Whooley MA. Depression and cardiovascular disease: healing the broken-hearted. JAMA (2006) 295:2874-81. doi:10.1001/jama.295.24.2874

92. Coloquin D, Bunker S, Clarke D, Glozier N, Hare D, Hickie I. Screening, referral and treatment of depression in patients with coronary heart disease. A consensus statement from the National Heart Foundation of Australia. Med J Aust (2013) 198:483-4. doi:10.5694/mja13.10153

93. Davidson KW. Depression and coronary heart disease. ISRN Cardiol (2012) 2012. doi: $10.5402 / 2012 / 743813$

94. Hare DL, Davis CR. Cardiac depression scale: validation of a new depression scale for cardiac patients. J Psychosom Res (1996) 40:379-86. doi:10.1016/0022-3999(95)00612-5

95. Dickens C, Mcgowan L, Percival C, Tomenson B, Cotter L, Heagerty A, et al. New onset depression following myocardial infarction predicts cardiac mortality. Psychosom Med (2008) 70:450-5. doi:10.1097/ PSY.0b013e31816a74de

96. Cohen BE, Edmondson D, Kronish IM. State of the art review: depression, stress, anxiety, and cardiovascular disease. Am J Hypertens (2015) 28(11):1295-302. doi:10.1093/ajh/hpv047

97. Mazza M, Lotrionte M, Biondi-Zoccai G, Abbate A, Sheiban I, Romagnoli E. Selective serotonin reuptake inhibitors provide significant lower re-hospitalization rates in patients recovering from acute coronary syndromes: evidence from a meta-analysis. J Psychopharmacol (2010) 24:1785-92. doi:10.1177/0269881109348176

98. Tata L, West J, Smith C, Farrington P, Card T, Smeeth L, et al. General population based study of the impact of tricyclic and selective serotonin reuptake inhibitor antidepressants on the risk of acute myocardial infarction. Heart (2005) 91:465-71. doi:10.1136/hrt.2004.037457

99. Zellweger MJ, Osterwalder RH, Langewitz W, Pfisterer ME. Coronary artery disease and depression. Eur Heart $J$ (2004) 25:3-9. doi:10.1016/j. ehj.2003.09.009
100. Baumeister H, Hutter N, Bengel J. Psychological and pharmacological interventions for depression in patients with coronary artery disease. Cochrane Database Syst Rev (2011) 9:CD008012. doi:10.1002/14651858. CD008012.pub3

101. Serebruany VL, Glassman AH, Malinin AI, Nemeroff CB, Musselman DL, Van Zyl LT, et al. Platelet/endothelial biomarkers in depressed patients treated with the selective serotonin reuptake inhibitor sertraline after acute coronary events: the Sertraline AntiDepressant Heart Attack Randomized Trial (SADHART) Platelet Substudy. Circulation (2003) 108:939-44. doi:10.1161/01.CIR.0000085163.21752.0A

102. ENRICHD Investigators. Enhancing Recovery in Coronary Heart Disease (ENRICHD) study intervention: rationale and design. Psychosom Med (2001) 63:747-55.

103. Skala JA, Freedland KE, Carney RM. Coronary heart disease and depression: a review of recent mechanistic research. Can J psychiatry (2006) 51:738.

104. Carney RM, Blumenthal JA, Stein PK, Watkins L, Catellier D, Berkman LF, et al. Depression, heart rate variability, and acute myocardial infarction. Circulation (2001) 104:2024-8. doi:10.1161/hc4201.097834

105. Fava M, Judge R, Hoog SL, Nilsson ME, Koke SC. Fluoxetine versus sertraline and paroxetine in major depressive disorder: changes in weight with longterm treatment. J Clin Psychiatry (2000) 61:863-7. doi:10.4088/JCP.v61n1109

106. Raeder MB, Bjelland I, Emil VS, Steen VM. Obesity, dyslipidemia, and diabetes with selective serotonin reuptake inhibitors: the Hordaland Health Study. J Clin Psychiatry (2006) 67:1974-82. doi:10.4088/JCP.v67n1219

107. Dannon PN, Iancu I, Cohen A, Lowengrub K, Grunhaus L, Kotler M. Three year naturalistic outcome study of panic disorder patients treated with paroxetine. BMC Psychiatry (2004) 4:16. doi:10.1186/1471-244X-4-16

108. Maina G, Albert U, Salvi V, Bogetto F. Weight gain during long-term treatment of obsessive-compulsive disorder: a prospective comparison between serotonin reuptake inhibitors. J Clin Psychiatry (2004) 65:1365-71. doi:10.4088/JCP.v65n1011

109. Li Z, Maglione M, Tu W, Mojica W, Arterburn D, Shugarman LR, et al. Meta-analysis: pharmacologic treatment of obesity. Ann Intern Med (2005) 142:532-46. doi:10.7326/0003-4819-142-7-200504050-00012

110. Pilling S, Anderson I, Goldberg D, Meader N, Taylor C. Depression in adults, including those with a chronic physical health problem: summary of NICE guidance. BMJ (2009) 339. doi:10.1136/bmj.b4108

111. Lichtman JH, Bigger JT, Blumenthal JA, Frasure-Smith N, Kaufmann PG, Lespérance F, et al. Depression and coronary heart disease recommendations for screening, referral, and treatment: a science advisory from the American Heart Association Prevention Committee of the Council on Cardiovascular Nursing, Council on Clinical Cardiology, Council on Epidemiology and Prevention, and Interdisciplinary Council on Quality of Care and Outcomes Research: endorsed by the American Psychiatric Association. Circulation (2008) 118:1768-75. doi:10.1161/CIRCULATIONAHA.108.190769

112. Hamer M, Batty GD, Seldenrijk A, Kivimaki M. Antidepressant medication use and future risk of cardiovascular disease: the Scottish Health Survey. Eur Heart J (2011) 32:437-42. doi:10.1093/eurheartj/ehq438

113. Witchel HJ, Hancox JC, Nutt DJ. Psychotropic drugs, cardiac arrhythmia, and sudden death. JClin Psychopharmacol (2003) 23:58-77. doi:10.1097/00004714-200302000-00010

114. Taylor D. Antidepressant drugs and cardiovascular pathology: a clinical overview of effectiveness and safety. Acta Psychiatr Scand (2008) 118:434-42. doi:10.1111/j.1600-0447.2008.01260.x

115. Follath F. [Depression, stress and coronary heart disease - epidemiology, prognosis and therapeutic sequelae]. Ther Umsch (2003) 60:697-701. doi:10.1024/0040-5930.60.11.697

116. Whalley B, Rees K, Davies P, Bennett P, Ebrahim S, Liu Z, et al. Psychological interventions for coronary heart disease. Cochrane Database Syst Rev (2011) 21:8. doi:10.1002/14651858.CD002902.pub3

117. Cooney GM, Dwan K, Greig CA, Lawlor DA, Rimer J, Waugh FR, et al. Exercise for depression. Cochrane Database Syst Rev (2013) 9:CD004366. doi:10.1002/14651858.CD004366.pub6

118. Dauwan M, Begemann MJ, Heringa SM, Sommer IE. Exercise improves clinical symptoms, quality of life, global functioning, and depression in schizophrenia: a systematic review and meta-analysis. Schizophr Bull (2015) sbv164. doi:10.1093/schbul/sbv164 
119. Milani RV, Lavie CJ, Cassidy MM. Effects of cardiac rehabilitation and exercise training programs on depression in patients after major coronary events. Am Heart J (1996) 132:726-32. doi:10.1016/S0002-8703(96)90304-X

120. Musselman DL, Marzec UM, Manatunga A, Penna S, Reemsnyder A, Knight BT, et al. Platelet reactivity in depressed patients treated with paroxetine: preliminary findings. Arch Gen Psychiatry (2000) 57:875-82. doi:10.1001/ archpsyc.57.9.875

121. Pollock BG, Laghrissi-Thode F, Wagner WR. Evaluation of platelet activation in depressed patients with ischemic heart disease after paroxetine or nortriptyline treatment. JClin Psychopharmacol (2000) 20:137-40. doi:10.1097/00004714-200004000-00004

Conflict of Interest Statement: The Human Neurotransmitters Laboratory is currently receiving research funding from National Health and Medical
Research Council of Australia and from Otsuka Pharmaceuticals. It has previously received research funding from Servier Pharmaceuticals. Dr. AD has received travel honoraria from Servier and Otsuka pharmaceuticals. Prof. DB has received honoraria for presentations from Eli Lilly, Servier, Pfizer, Solway Pharmaceuticals, Wyeth Pharmaceuticals, Lundbeck, and AstraZeneca. He has received research funding from Servier, Pfizer, Eli Lilly, Otsuka, and Lundbeck.

Copyright (c) 2016 Dhar and Barton. This is an open-access article distributed under the terms of the Creative Commons Attribution License (CC BY). The use, distribution or reproduction in other forums is permitted, provided the original author(s) or licensor are credited and that the original publication in this journal is cited, in accordance with accepted academic practice. No use, distribution or reproduction is permitted which does not comply with these terms. 